\title{
Authors' response: Measles outbreak linked to an international dog show in Slovenia, 2014
}

M Grgič-Vitek (Marta.Vitek@nijz.si) ${ }^{1}$, on behalf of the authors of the original article ${ }^{2}$

1. Communicable Diseases Centre, National Institute of Public Health (NIJZ), Ljubljana, Slovenia

2. http://www.eurosurveillance.org/ViewArticle.aspx?Articleld=21012

Grgič-Vitek M, on behalf of the authors of the original article. Authors' response: Measles outbreak linked to an international dog show in Slovenia, 2014. Euro Surveill. 2015;20(9):pii=21052. Available online: http://www.eurosurveillance.org/ViewArticle.aspx?Articleld=21052

\section{To the editor:}

The letter by Filia et al. [1] provides interesting additional information on the measles outbreak linked to an international dog show, reported in our paper recently published in Eurosurveillance [2]. After its publication, no additional measles cases linked to this outbreak were reported in Slovenia, and the number has remained at 44. Together with 18 Italian cases and one detected in Belgium, this gives a total of 63 measles cases linked to this outbreak.

In addition to data on measles cases, the Italian authors have also provided data on age and vaccination status of the participants at the dog show. In Slovenia, we only focused on measles cases and contact tracing; demographic information for the Slovenian participants at the dog show was not available. The median age of participating population from Italy was 45 years, five years higher than the median age of the cases reported in Slovenia. Data on vaccination status of the Slovenian participants were not available. The majority $(77.1 \%)$ of the Italian participants was unvaccinated. In Slovenia, vaccination coverage was high during the last decades, thus we assume that a smaller proportion of the participants were unvaccinated since also the proportion of unvaccinated cases was smaller (23/44; 52\%).

When comparing the median age of Italian and of Slovenian measles cases, our cases were older (31 in Italy as compared with 40 years of age in Slovenia). In addition, the vaccination status of the cases was different: among Italian cases only two (11\%) were vaccinated with one dose, while nearly half (21/44) of the Slovenian cases were vaccinated with one (nine cases) or two (12 cases) doses. It is interesting to note that among 18 Italian measles cases detected, there were mostly women, only two cases were in men (though $47.4 \%$ of participants were male), while nearly half $(19 / 44)$ of the Slovenian cases were male.

Molecular characterisation of viruses from cases linked to international mass gatherings is important for tracing international measles virus transmission pathways, but not always helpful in identifying country of origin. Namely, in 2014, measles virus D8 (with exact matching sequence) has been identified in many European countries [2]. In Slovenia, D8 genotype was also observed in one of the cases linked to the outbreak in Bosnia and Herzegovina which were reported in the same period (November to December 2014) [2].

It is worth mentioning that there was another dog show in Ljubljana in January 2015, and on this occasion information leaflets about possible risk of measles and with immunisation advice were prepared and distributed for the participants, as suggested by the World Health Organization (WHO) [3] and highlighted by Italian authors. No measles cases were linked to this event.

On the way to measles elimination, different countries will have to implement different strategies, depending on their phase of elimination. In countries like Italy, it will probably be most important to increase and sustain high measles vaccination coverage. If global elimination is not going to be achieved soon, some countries may be confronted with new challenges in the future. In countries like Slovenia, where vaccination against measles started early (1968), and the coverage was high through decades, the absence of circulating virus and periodic boosting may result in waning immunity in the population vaccinated decades ago, altering the paradigm of lifelong immunity, as suggested earlier $[4,5]$. In this situation, additional strategies in some countries may be needed, such as recommending a third dose of measles-containing vaccine for some age groups.

Conflict of interest

None declared.

Authors' contributions

Marta Grgič Vitek wrote the letter on behalf of the authors of the original article. 


\section{References}

1. Filia A, Riccardo F, Del Manso M, D’Agaro P, Magurano F, Bella A, et al. Letter to the editor: Measles outbreak linked to an international dog show in Slovenia - primary cases and chains of transmission identified in Italy, November to December 2014. Euro Surveill. 2015;20(9):pii=21050. Available from: http://www.eurosurveillance.org/ViewArticle. aspx?Articleld $=21050$

2. Grgič-Vitek M, Frelih T, Učakar V, Fafangel M, Jordan Markocic $\mathrm{O}$, Prosenc K, et al. An outbreak of measles associated with an international dog show in Slovenia, November 2014. Euro Surveill. 2015;20(3):21012. http://dx.doi.org/10.2807/15607917.ES2015.20.3.21012. PMID:25635318

3. World Health Organization (WHO). Communicable disease alert and response for mass gatherings. Key considerations. June 2008. Geneva: WHO. Available from: http://www.who.int/csr/ Mass_gatherings2.pdf

4. Rota JS, Hickman CJ, Sowers SB, Rota PA, Mercader S, Bellini WJ. Two case studies of modified measles in vaccinated physicians exposed to primary measles cases: high risk of infection but low risk of transmission. J Infect Dis. 2011;204(Suppl 1):S559-63. http://dx.doi.org/10.1093/infdis/ jiro98 PMID:21666213

5. Chen RT, Markowitz LE, Albrecht P, Stewart JA, Mofenson LM, Preblud SR, et al. Measles antibody: reevaluation of protective titers. J Infect Dis. 1990;162(5):1036-42. http://dx.doi. org/10.1093/infdis/162.5.1036 PMID:2230231 